\title{
DEZ ANOS DA CLÍNICA FITOSSANITÁRIA DA UFLA - FREQÜÊNCIA DA OCORRÊNCIA DE PATÓGENOS, SINTOMAS E PRINCIPAIS HOSPEDEIROS
}

\author{
VIVIANE TALAMINI ${ }^{1}$ \\ EDSON AMPÉLIO POZZA ${ }^{2}$ \\ PAULO ESTEVÃO DE SOUZA ${ }^{2}$ \\ DANIEL GARCIA JÚNIOR ${ }^{1}$ \\ HILÁRIO ANTÔNIO DE CASTRO ${ }^{2}$ \\ RICARDO MAGELA DE SOUZA ${ }^{2}$ \\ MÁRIO SOBRAL DE ABREU ${ }^{2}$
}

\begin{abstract}
RESUMO - Com o presente trabalho objetivou-se analisar os diagnósticos realizados na Clínica Fitossanitária do Departamento de Fitopatologia da Universidade Federal de Lavras, no período de 1990 a 1999. Foram analisadas 85 espécies de hospedeiros, num total de 1429 amostras. Os fungos, com $70,5 \%$, as bactérias, com $12,9 \%$ e as viroses, com $1,2 \%$, foram os agentes etiológicos de doenças bióticas encontrados com maior frequiência. A deficiência nutricional e a fitotoxidez representaram 15,4\%. O fungo de maior ocorrência foi o gênero Fusarium, associado a 25,5\% das doenças, seguido de Colletotrichum (16\%), Rhizoctonia (11\%), Alternaria (5\%), Cercospora (4\%), espécies do grupo Helminthosporium (4\%) e Phoma $(3,5 \%)$. Os demais gêneros de fungos representa-
\end{abstract}

TERMOS PARA INDEXAÇÃO: Doenças de plantas, clínica fitossanitária e epidemiologia.

\section{TEN YEARS OF PLANT DISEASE CLINIC AT UFLA - FREQUENCY OF THE PATHOGENS, SYMPTOMS AND MAIN ANALYZED CULTURES}

\begin{abstract}
This work had as objective analyzes the diagnoses accomplished at the Plant Disease Clinic of the Plant Pathology Department at the Federal University of Lavras, between 1990 to 1999 . Eighty five hosts were analyzed, in 1429 samples. The fungus with $70.5 \%$, the bacteria with $12.9 \%$ and the viroses with $1.2 \%$ were the etiologic agents found more frequently. The fungi etiologic agent of larger occurrence was the genera Fusarium associated to $25.5 \%$ of the diseases, followed by Colletotrichum (16\%), Rhizoctonia (11\%), Alternaria (5\%), Cercospora (4\%), Helminthosporium (3.5\%) and Phoma (3\%), the other fungi agents represented $31 \%$ of
\end{abstract}

the samples. The bacterial etiologic agent of larger occurrence was the Erwinia genera with $35 \%$ of samples, followed to genera Streptomyces (30\%), Ralstonia (13,5\%), Pseudomonas (11.5\%), Xanthomonas $(9.5 \%)$ and Agrobacterium (0.5\%). The leaves spots were the symptoms of larger occurrence, with $40 \%$ of the samples, followed by wilts $(22 \%)$, cankers and scab (17\%), rots (14\%) and damping-of (3\%). Concernings the hosts, the vegetables stood out with $27 \%$ of the occurrences, the grains with $24 \%$, the tropical fruits with $17 \%$, the ornamental ones with $15 \%$, the temperate fruits with $3 \%$, forage with $2 \%$, oleaginous with $2 \%$ and other with $10 \%$. (13,5\%), Pseudomonas (11,5\%), Xanthomonas (9,5\%) e Arobacterium (0,5\%). As manchas foliares foram os sinmostras recebidas, seguidas das murchas $(22 \%)$, cancros e sarnas $(17 \%)$, podridões $(14 \%)$ e tombamento $(3 \%)$. Outre os hospedeiros, as hortaliças destacaram-se com $27 \%$ radas, com $3 \%$, forrageiras, com $2 \%$, oleaginosas, com $2 \%$ e outros, com $10 \%$

INDEX TERMS: Plant disease, plant pathology clinic and epidemiology.

1. Estudante do programa de pós-graduação em Fitopatologia da UNIVERSIDADE FEDERAL DE LAVRAS/UFLA, Caixa Postal 37, 37200-000, Lavras, MG.

2. Professor do Departamento de Fitopatologia da UFLA, eapozza@ufla.br 


\section{INTRODUÇÃO}

As plantas, principalmente as cultivadas pelo homem, são suscetíveis a diversas doenças, as quais podem reduzir a produtividade ou até mesmo dizimar espécies vegetais em determinada área. Tanto doenças bióticas, quanto doenças abióticas podem comprometer a produção e a produtividade, resultando em perdas significativas que culminam em graves prejuízos para produtores e consumidores (Agrios, 1997). A magnitude das perdas é condicionada ao tipo de cultura, ao patógeno, à localidade, ao ambiente e às medidas de controle. Enfim, os produtos agrícolas podem sofrer perdas em razão da simples ocorrência das doenças no campo, ou durante o armazenamento e o transporte (Pozza, 1994).

Um dos principais problemas encontrados atualmente pelos extensionistas é a dificuldade na diagnose de doenças de plantas ou até mesmo, em alguns casos, a dificuldade em distinguir uma deficiência nutricional ou fitoxidez de uma doença. A diagnose correta de doenças pode auxiliar produtores e profissionais da área agrícola a evitar o erro e a conseqüiente recomendação inadequada de medidas de controle, principalmente no uso de defensivos agrícolas. Uma alternativa para realizar o diagnóstico correto é procurar o auxílio de especialistas ou de Clínicas Fitossanitárias (CF). As CF, por sua vez, ao longo dos anos, podem reunir informações valiosas sobre as dúvidas de maior frequiência dos extensionistas, em relação à etiologia, sintomas ou hospedeiros de maior ocorrência, entre outras. Certamente, as CF possuem em seus arquivos dados de levantamento sobre as principais doenças de determinada região. Em outros países, essas informações permitem avaliar a importância de doenças, associadas a diversos patógenos. No Brasil, entretanto, trabalhos de levantamento de doenças de plantas, quer por grupo de espécies, quer para espécie individual, são escassos (Gomide, 1989; Pozza et al., 1999).

De acordo com o exposto, objetivou-se com o presente trabalho demonstrar a frequiência dos agentes etiológicos, dos gêneros de fungos e bactérias e dos hospedeiros catalogados na Clínica Fitossanitária do Departamento de Fitopatologia da UFLA, durante dez anos de trabalhos.

\section{MATERIAL E MÉTODOS}

Foi realizado um levantamento da frequiência da ocorrência de patógenos, sintomas e principais hospedeiros de amostras analisadas na Clínica Fitossanitária do Departamento de Fitopatologia da UFLA, com base em dados catalogados em arquivo entre 1990 e 1999. Esse arquivo foi disponibilizado em banco de dados Access ${ }^{\circledR}$ (Microsoft Inc.) e dividido por agente etiológico, gênero do patógeno, cultura e local de ocorrência. Inicialmente, os materiais doentes, recebidos na $\mathrm{CF}$, passaram por triagem, de modo a separar doenças de natureza biótica daquelas de natureza abiótica, por meio da análise dos sintomas, baseando-se na literatura básica como, Barnett et al. (1987), Pitta et al. (1990), Hawksworth et al. (1995), Kimati et al. (1997), Ponte (1996), Mendes et al. (1998), boletins técnicos, compêndios de doenças de plantas da sociedade Americana de Fitopatologia e consultas no herbário "Prof. Josué Augusto Deslandes", do Departamento de Fitopatologia da Universidade Federal de Lavras.

As amostras com doenças de natureza biótica foram submetidas à avaliação preliminar, para identificar o agente etiológico (fungo, bactéria, vírus ou nematóide). Em seguida, foram encaminhadas aos laboratórios de pesquisa específicos, como bacteriologia e virologia, onde foram submetidos a testes para identificação do patógeno. Para identificar os fungos, as plantas foram examinadas, no laboratório de controle de enfermidades fúngicas, ao microscópio estereoscópico, e lâminas foram preparadas pelo método direto a partir do próprio material doente e visualizadas ao microscópio óptico. Quando não foi possível a imediata identificação, o material foi colocado em câmara úmida e/ou procedeu-se ao isolamento do fungo em meio BDA (Batatadextrose-agar) e/ou Ágar-água e/ou PCA (Potatocarrot-agar), segundo as técnicas descritas por Kirally et al. (1974). Os materiais analisados que não apresentavam evidências de doenças conhecidas foram submetidos aos "postulados de Koch", para confirmar o estabelecimento da relação etiológica doença-patógeno.

Os materiais com suspeita de infecção por bactérias, e que apresentavam sintomas como exsudação, podridão mole e congestionamento de água nos tecidos infectados, foram submetidos a testes de exsudação em gota ou corrida bacteriana (Romeiro, 1995). Plantas com necrose ou murcha vascular foram submetidas ao teste de corrida em bordo de copo. As amostras com resultados positivos foram submetidas ao isolamento em meio 523 de Kado \& Heskett (1970). Após o crescimento, foram observadas a pureza do isolamento, cor e morfologia das colônias, pigmentação fluorescente e teste de anaerobiose, além de outros testes bioquímicos para a caracterização do gênero. Para identificar Xylella fastidiosa Wells, utilizou-se a técnica de PCR (Polimerase Chain Reaction). As viroses foram identificadas por sintomatologia, inoculação em plantas indicadoras e testes sorológicos como DAS-ELISA. 


\section{RESULTADOS E DISCUSSÃO}

No período de janeiro de 1990 a dezembro de 1999, foram analisadas 85 espécies de hospedeiros, num total de 1429 amostras recebidas pela Clínica Fitossanitária da UFLA. Os fungos, com 70,5\%, as bactérias, com $12,9 \%$, e os vírus, com $1,2 \%$, foram os agentes etiológicos de doenças bióticas encontrados com maior frequiência. A deficiência nutricional e a fitotoxidez representaram 15,4\% das amostras recebidas (Figura 1).

Pelos resultados encontrados, observa-se similaridade com as afirmativas feitas por Agrios (1997). Esse autor também relatou os fungos como os agentes etiológicos de maior ocorrência em doenças de plantas.

Os fungos, agentes etiológicos de maior ocorrência, apresentaram percentual de $70,5 \%$, concordando com os resultados obtidos por Zambolim \& Ribeiro do Vale (1985) e Pozza et al. (1999), os quais afirmaram ser os fungos os principais responsáveis pelas doenças em grandes culturas. O manejo inadequado das lavouras, mais uma vez, mostrou-se evidente, destacando-se a deficiência nutricional e a fitoxidez, totalizando juntas 15,4\% das amostras recebidas pela Clínica Fitossanitária da UFLA, no período analisado.

O agente etiológico fúngico de maior ocorrência foi o gênero Fusarium, destacando-se as espécies F. oxysporum (Schlecht.) Snyder \& Hansen e F. sola$n i$ (Mart.) Sac., associados a 25,5\% das doenças, seguido dos gêneros Colletotrichum (16\%), Rhizoctonia (11\%), Alternaria (5\%), Cercospora (4\%), Helminthosporium (4\%) e Phoma (3,5\%). Os demais gêneros de fungos representaram $31 \%$ das amostras (Figura 2).
O sintoma murcha esteve entre os de maior ocorrência, provavelmente em razão da dificuldade do produtor ou extensionista de identificar o agente etiológico da murcha no campo. Outros quadros sintomatológicos expressos por sinais, como ferrugens e oídios e seus respectivos agentes etiológicos, obtiveram baixa freqüência, certamente devido à facilidade na diagnose.

Entre os agentes etiológicos bacterianos, destacou-se o gênero Erwinia, com 35\% das amostras, seguido pelos gêneros Streptomyces (30\%), Ralstonia (13,5\%), Pseudomonas (11,5\%), Xanthomonas (9,5\%) e Agrobacterium (0,5\%) (Figura 3).

As manchas foliares foram os sintomas de maior ocorrência (Figura 4), sendo encontradas em 40\% das amostras recebidas, seguidas das murchas $(22 \%)$, cancros e sarnas $(17 \%)$, podridões $(14 \%)$, tombamento $(3 \%)$. Outros sintomas foram encontrados em $4 \%$ das amostras recebidas pela Clínica no mesmo período descrito acima. As manchas foliares apresentaram menor percentual do que o encontrado por Pozza et al. (1999). Esses autores encontraram freqüência de 48,9\% de manchas foliares em levantamento realizado no município de Lavras-MG, entre 1993 e 1994. Essa maior porcentagem foi devida ao fato de o município não ter plantações de batata, pois amostras dessa cultura foram recebidas em maior número pela Clínica a partir de 1998. O agente etiológico associado ao maior número de lesões foliares foi Colletotrichum, ao passo que $\mathrm{Fu}$ sarium foi encontrado associado ao maior número de sintomas de murcha, como verificado também por Pozza (1994). Os gêneros Rhizoctonia e Streptomyces foram encontrados com maior freqüência em órgãos de armazenamento, principalmente em tubérculos de batata.

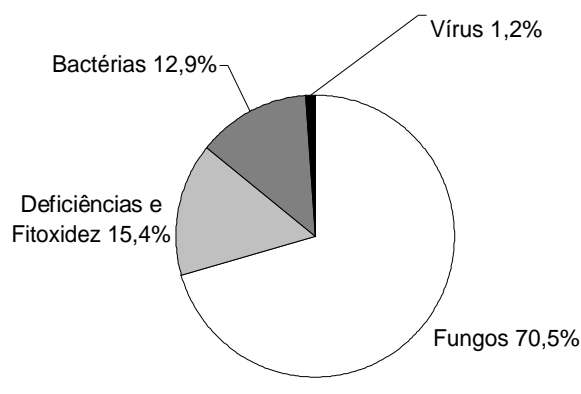

FIGURA 1 - Frequiência da ocorrência de agentes etiológicos bióticos e abióticos em amostras recebidas na Clínica Fitossanitária do DFP/UFLA entre janeiro de 1990 e dezembro de 1999.

Ciênc. agrotec., Lavras. V.27, n.1, p.70-75, jan./fev., 2003 


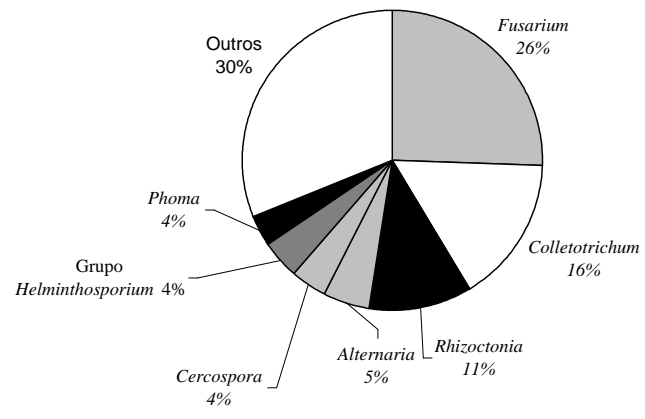

FIGURA 2 - Frequiência da ocorrência de gêneros de fungos associados às amostras recebidas pela Clínica Fitossanitária do DFP/UFLA entre janeiro de 1990 e dezembro de 1999.

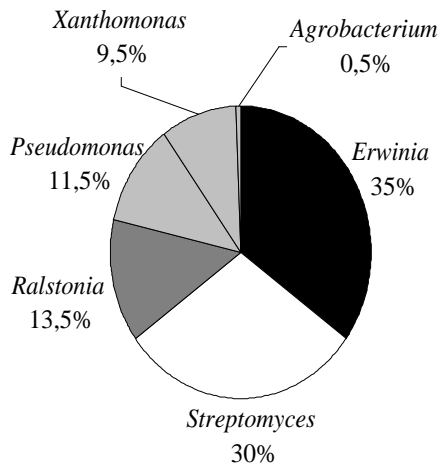

FIGURA 3 - Freqüência da ocorrência de gêneros bacterianos associados às amostras recebidas pela Clínica Fitossanitária do DFP/UFLA entre janeiro de 1990 e dezembro de 1999

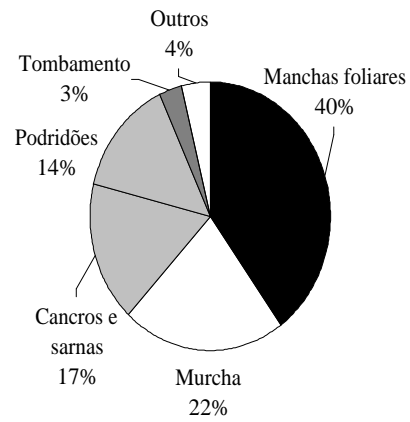

FIGURA 4 - Freqüência da ocorrência de sintomas e sinais associados a amostras recebidas pela Clínica Fitossanitária do DFP/UFLA entre janeiro de 1990 e dezembro de 1999.

Ciênc. agrotec., Lavras. V.27, n.1, p.70-75, jan./fev., 2003 


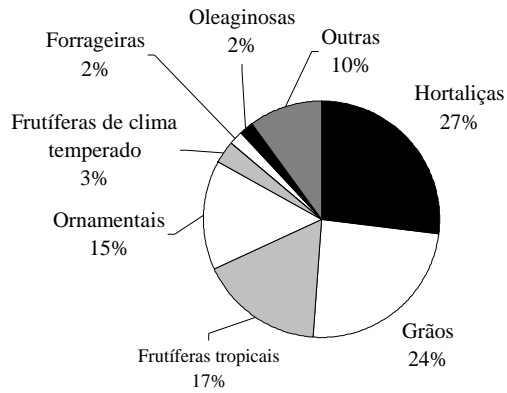

FIGURA 5 - Freqüência de hospedeiros doentes recebidos pela Clínica Fitossanitária do DFP/UFLA entre janeiro de 1990 e dezembro de 1999.

As hortaliças apresentaram o maior número de doenças, totalizando $27 \%$ das amostras recebidas. No entanto, apresentaram menor percentual do que o encontrado por Pozza et al. (1999), em levantamentos realizados na Clínica Fitossanitária da UFLA, nos períodos de 1992 a 1993 e 1990 a 1994, respectivamente. O resultado condiz com a realidade, pois Pozza et al. (1999) realizaram levantamento somente no município de Lavras-MG, enquanto outros descreveram todas as amostras recebidas pela Clínica Fitossanitária. Os grãos apresentaram o segundo maior percentual $(23 \%)$, seguido das frutíferas tropicais $(17 \%)$, ornamentais (14\%), frutíferas de clima temperado (3\%), forrageiras $(2 \%)$, oleaginosas $(2 \%)$ e outras culturas com 9\% (Figura 5). O café foi o hospedeiro com maior número de amostras recebidas pela Clínica Fitossanitária da UFLA, provavelmente pelo fato de a mesma estar localizada na principal região produtora do País.

\section{CONCLUSÕES}

a) Em 1429 amostras recebidas pela Clínica Fitossanitária do DFP/UFLA, foram identificadas doenças cujos agentes etiológicos foram fungos, bactérias e vírus, além de deficiências minerais, queima pelo sol e toxidez por nutrientes, agrotóxicos e hormônios.

b) Os patógenos de maior ocorrência foram os fungos, representando $70,5 \%$ do total, principalmente os mitospóricos, os quais estavam associados a mais de $68 \%$ das doenças fúngicas. c) Os gêneros de fungos de maior ocorrência foram Fusarium, associado a $25,5 \%$ das doenças, seguido de Colletotrichum (16\%) e Rhizoctonia (11\%).

d) Entre os agentes etiológicos bacterianos, destacou-se o gênero Erwinia, com $35 \%$ das ocorrências, seguido pelos gêneros Streptomyces (30\%), Ralstonia (13,5\%), Pseudomonas (11,5\%) e Xanthomonas (9,5\%).

e) As manchas foliares foram os sintomas de maior ocorrência (40\%), seguidas das murchas, representando $22 \%$.

f) Os hospedeiros com maior número de amostras analisadas foram as hortaliças, com $27 \%$ das ocorrências, os grãos $(24 \%)$, as frutas tropicais $(17 \%)$ e as plantas ornamentais $(15 \%)$.

\section{REFERÊNCIAS BIBLIOGRÁFICAS}

AGRIOS, G. N. Plant pathology. New York, Academic Press, 1997. 635 p.

BARNETT, H. L.; HUNTER, B. B. Illustrated genera of imperfect fungi. 4. ed. New York: Macmillan, 1987. $218 \mathrm{p}$.

GOMIDE, A. F. Levantamento de doenças bacterianas em hortaliças na região do cinturão verde de Belo Horizonte. 1989. 89 p. Dissertação (Mestrado em Fitossanidade) - Universidade Federal de Viçosa, Viçosa.

HAWKSWORTH, D. L.; KIRK, P. M.; SUTTON, B. C.; PEGLER, D. N. Dictionary of the fungi. Wallingford: [s.n.], 1995. 616 p. 
KADO, C. I.; HESKETT, M. G. Selective media for isolation of Agrobacterium, Corynebacterium, Erwinia, Pseudomonas e Xanthomonas. Phytopathology, Saint Paul, v. 60, n. 6, p. 969-976, jun. 1970.

KIMATI, H.; AMORIM, L.; BERGAMIN FILHO, A.; CAMARGO, L. E. A.; REZENDE, J. A. M. Manual de fitopatologia: volume 2: doenças de plantas cultivadas. São Paulo: Agronômica Ceres, 1997. 775 p.

KIRALLY, Z.; KLEMENT, Z.; SOLYMOSY, F. et al. Methods in plant pathology. Budapeste: Akad.Kiadó, 1974. $609 \mathrm{p}$.

MENDES, M. A. S.; SILVA, V. L.; DIANESE, J. C.; FERREIRA, M. A. S. V.; SANTOS, C. E. N.; NETO, E. G.; URBEN, A. F.; CASTRO, C. Fungos em plantas no Brasil. Brasília: Embrapa-Cenargem, 1998. 569 p.

PITTA, C. P. B.; CARDOSO, R. M. G.; CARDOSO, E. J. B. N. Doenças das plantas ornamentais. São Paulo, IBLC, 1990. $176 \mathrm{p}$.

PONTE, J. J. Clínica de doenças de plantas. Fortaleza: EUFC, 1996. 872 p.
POZZA, E. A. Ocorrência de doenças da parte aérea de plantas na região de Lavras-MG. 1994. 97 p. Dissertação (Mestrado em Fitossanidade) - Universidade Federal de Lavras, Lavras.

POZZA, E. A.; SOUZA, P. E.; CASTRO, H. A; POZZA, A. A. A. Freqüência da ocorrência de doenças de plantas na região de Lavras-MG. Ciência e Agrotecnologia, Lavras, v. 23, n. 4, p. 1002-1006, out./dez., 1999.

POZZA, E. A.; SOUZA, P. E.; BRITO, C. H.; CARDOSO, M. A. F. C. Ocorrência de fungos associados a doenças em plantas ornamentais em Lavras-MG. Ciência e Agrotecnologia Lavras, v. 20, n. 1, p. 39-44, jan./mar., 1996.

ROMEIRO, R. S. Bactérias fitopatogênicas. Viçosa: UFV-Imprensa Universitária, 1995. 283 p.

ZAMBOLIM, L.; RIBEIRO DO VALE, F. X. Perdas ocasionadas pelas doenças de plantas. Informe Agropecuário, Belo Horizonte, v. 11, n. 131, p. 56-64, nov. 1985. 